\title{
Intestinal permeability studies for piperaquine from dihydroartemisinin-piperaquine antimalarial product in the presence of lamivudine
}

\author{
Sunday O. Awofisayo ${ }^{1^{*}}$, Ayodeji A. Agboke ${ }^{2}$, Ekpedeme N. Essien ${ }^{1}$, Chioma N. Igwe ${ }^{1}$ \\ ${ }^{1}$ Department of Clinical Pharmacy and Biopharmacy, Faculty of Pharmacy, University of Uyo, Uyo, Nigeria. \\ ${ }^{2}$ Department of Pharmaceutics and Pharmaceutical Technology/Pharmaceutical Microbiology, Faculty of Pharmacy, University of Uyo, Uyo, Nigeria.
}

\begin{tabular}{|c|c|}
\hline ARTICLE INFO & ABSTRACT \\
\hline $\begin{array}{l}\text { Received on: } 12 / 03 / 2018 \\
\text { Accepted on: } 20 / 08 / 2018 \\
\text { Available online: } 30 / 11 / 2018\end{array}$ & $\begin{array}{l}\text { The study assessed the intestinal permeability of piperaquine (PQ) from dihydroartemisinin-piperaquine (DP) } \\
\text { antimalarial in the presence of lamivudine (LMV). Excised tissues (duodenum and ileum) from New Zealand male } \\
\text { albino rabbits }(n=2) \text { were loaded with a suspension of DP equivalent to PQ }(100 \mathrm{mg} / \mathrm{ml}) \text { and LMV }(100 \mathrm{mg} / \mathrm{ml}) \\
\text { and submerged in Tyrode solution (TS). DP suspension was similarly loaded as control. Sampling (5 ml) of TS was }\end{array}$ \\
\hline $\begin{array}{l}\text { Key words: } \\
\text { Dihydroartemisinin-- } \\
\text { piperaquine, piperaquine, } \\
\text { lamivudine, permeability, } \\
\text { intestinal membrane. }\end{array}$ & 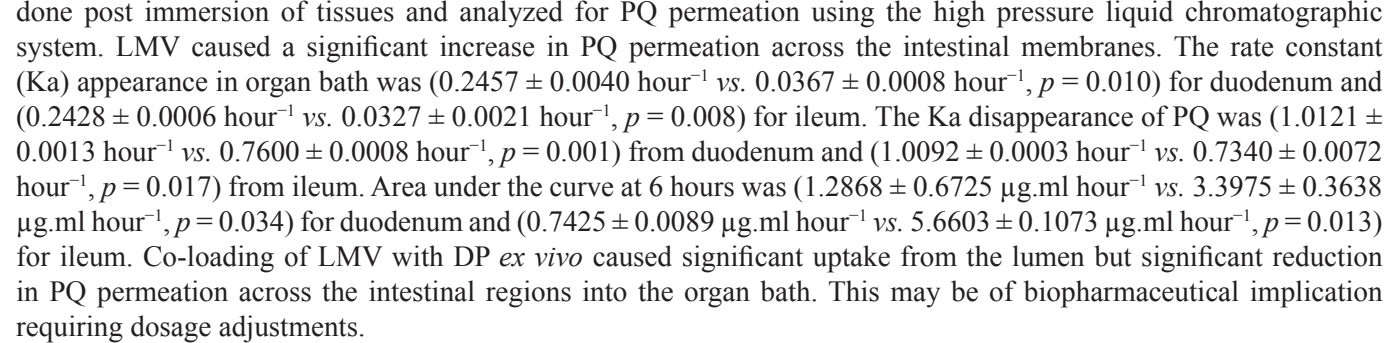 \\
\hline
\end{tabular}

\section{INTRODUCTION}

Ex-vivo studies involving stomach and intestinal segments have been extensively reported as a model for assessing the permeation or diffusion of drug molecules across absorptive membranes (Luo et al., 2013). This model serves as a preliminary evaluation of oral drug absorption and its mechanisms (Li et al.,2014). Orally administered pharmacologic agents are required to possess favorable absorption indices (Shugart and Benet, 2009). Several factors can affect absorption and consequently the bioavailability of drugs which include physicochemical and physiological

*Corresponding Author

Sunday O. Awofisayo, Department of Clinical Pharmacy and Biopharmacy, Faculty of Pharmacy, University of Uyo, Uyo, Nigeria. E-mail: sundayawofisayo@uniuyo.edu.ng considerations (Antunes et al., 2013). Most poorly water-soluble agents with demonstrable pharmacologic usefulness have been assessed for their therapeutic benefits (Gupta and Sehrawat, 2011). In recent times, real-life situation studies require the combination of information from different sources in experimental design to describe the in vivo scenario of drug applicability (Chapman and Wilson, 2013). The conditions under which a drug is evaluated for disintegration, dissolution, and absorption may preclude that which obtains when such agents are co-administered due to co-prescribing with other drugs (CDER, 2012).

Dihydroartemisinin-piperaquine (DP) is a cost-effective and well-prescribed drug for the treatment of uncomplicated Plasmodium falciparum malaria (Mori et al., 2014). DP has been recommended by the World Health Organization for the treatment of multi-drug resistant $P$. falciparum malaria. Malaria is a life-threatening parasites infection which can co-exist with Human Immunoviral (HIV) infection, thereby requiring the co- 
prescribing of antimalarial and antiretroviral agents (German et al., 2007; Uriel and Lewihwaite, 2011; Qureshi, 2016). Malaria has also been reported as the third leading cause of death in HIV positive individuals (Foca et al., 2012). Artemisinin-combination therapy has been reported to account for a significant proportion of clinically significant drug interactions with antiretroviral drugs (Oshikoya et al., 2014). In view of the arguments, lamivudine (LMV), a nucleoside reverse transcriptase inhibitor may be coprescribed with piperaquine (PQ) in cases of co-morbidities (DHHS, 2017; Zhang et al., 2011).

A detailed review of possible concomitantly prescribed medications is required when selecting an antiretroviral, especially in cases of co-infections so as to avoid untoward drug-drug interactions (DDI) (Piscitelli and Galliciano, 2001). Integrase Strand Transfer Inhibitors (INSTIs) have the potential for decreased absorption from the gastrointestinal tract by polyvalent cations. It is recommended to give INSTIs at least 2 hours before or at least 6 hours after supplements containing polyvalent cations (Tseng, 2015). Similarly, LMV has been reported to cause pancreatitis resulting in increased intestinal motility. This may affect the absorption of concurrently administered drugs by a physiological mechanism.

This study aimed at assessing the effect of coadministration of LMV with DP on PQ permeation across the intestinal absorptive membrane.

\section{MATERIALS AND METHODS}

\section{Materials}

Pure reference sample of piperaquine phosphate and tinidazole was obtained from Central Research Laboratory, University of Lagos, Nigeria. High-Pressure Liquid Chromatographic (HPLC) grade acetonitrile and ammonium acetate were the products of Sigma Aldrich, Germany. Sodium chloride, potassium chloride, calcium chloride, magnesium chloride, and sodium bicarbonate were the products of Sigma Aldrich Germany.

The drug products used were P-alaxin ${ }^{\circledR}$ and LMV tablets, products of Bliss GVC and Healthy Life Pharma, India, respectively. Distilled water was used throughout the study.

\section{Preparation of standard solutions/physiologic solution}

A powder weight of $50 \mathrm{mg}$ reference standard PQ was taken and dissolved in $10 \mathrm{ml}$ volumetric flask to prepare a $5 \mathrm{mg} / \mathrm{ml}$ stock solution. Serial dilutions of stock solution were made to produce graded concentrations in the range $1-100 \mathrm{mg} /$ $\mathrm{ml}$. The appropriate proportions of salts (i.e., sodium chloride, potassium chloride, calcium chloride, magnesium chloride, sodium bicarbonate, and glucose) were dissolved to prepare 2.51 of Tyrode solution (TS) according to standard TS preparation protocols.

\section{Preparation of solutions of drugs/admixture of investigated drugs}

Five tablets of each drug product (i.e., DP and LMV) were weighed and the respective mean weight obtained. The equivalent weights corresponding to the labeled claim of active ingredients were employed to calculate the amount of drug products (in powder) required to obtain a concentration of 100 $\mathrm{mg} / \mathrm{ml}$. The admixture of DP and LMV solutions were produced based on the doses for each drug per kg of rabbit weight.

\section{Handling of animals}

New Zealand albino male rabbits $(n=2)$ were employed for the study. Animals were fed with standard pellet diet for 1 week while allowing them to acclimatize with the environment. Animals were allowed access to water ad libitum. The animals were fasted for 2 days prior to the experiment. The protocol of the study was approved by the Faculty of Pharmacy, University of Uyo Ethics Committee on the Use of Laboratory Animals (UFP012). Good Laboratory Practice was observed throughout the study. The animals were handled based on the American Psychological Associations Guidelines for Ethical Conduct in the Care and Use of Non-human Animals in Research (AMA, 2010).

\section{Preparation of tissues and organ bath set up}

Organ bath containing $100 \mathrm{ml}$ of TS was set up with a mechanical aerator in place. Animals were paralyzed by cervical dislocation and subsequently, the abdomen was exposed to ligate the duodenum (region after the stomach) and the ileum (region before the ileocecal junction). The tissues for the intestinal segments were cut into segments of $4 \mathrm{~cm}$ each.

\section{Loading of tissues and sampling}

One end of excised tissue was tied with silk thread while the investigated solution was loaded before tying the other end, based on animal body weight (i.e., $10.66 \mathrm{mg}$ of $\mathrm{PQ} / \mathrm{kg}$ and $4 \mathrm{mg}$ of $\mathrm{LMV} / \mathrm{kg})$. Sampling $(5 \mathrm{ml})$ was taken at $0,0.5,1,2,4$, and 6 hours with the replacement of equal amount of fresh TS solution. The samples were filtered using $0.45 \mu \mathrm{m}$ Acrodisc syringe filter and filtrate stored in ultra-freezer at $-20^{\circ} \mathrm{C}$ pending analysis.

\section{High-pressure liquid chromatographic analysis}

Samples were analyzed on a Chemstation HPLC system equipped with a UV detector. A C8 Zorbact XDB reverse phase $(150 \times 4.6 \mathrm{~mm}, 4.6 \mu \mathrm{m})$ column was employed for the chromatographic analysis. The mobile phase consisted of acetonitrile and $10 \mathrm{mM}$ ammonium acetate $(70: 30, \% \mathrm{v} / \mathrm{v})$ while the wavelength of detection and flow rate were $220 \mathrm{~nm}$ and 0.7 $\mathrm{ml} /$ minute, respectively. The injection volume was $1 \mu \mathrm{l}$ and the column was maintained at $20^{\circ} \mathrm{C}$ throughout the analysis.

\section{Pharmacokinetic and statistical analysis}

The deduced PQ concentration of samples was computed and analyzed with APK pharmacokinetic software version 13 (Rxkinetics, USA). Significant differences between the pharmacokinetic parameters derived for treatments were compared and analyzed using Paired $T$-test employing SPSS version 20 (IBM, USA) and the significance level was set at alpha $=5 \%$ (i.e., $p=0.05$ ) for all comparisons.

\section{RESULTS}

A representative chromatograph of the PQ is presented in Figure 1. Peaks for the concentration of PQ and IS were clearly portrayed in the chromatographs with peaks for PQ and IS at about 4.3 and 2.2 minutes, respectively. PQ concentration time curves for the experimental conditions are presented in Figure 2. LMV caused a decrease in the permeation of PQ in both intestinal regions. The effective permeability coefficient $\left(P_{\text {eff }}\right)$ for PQ 


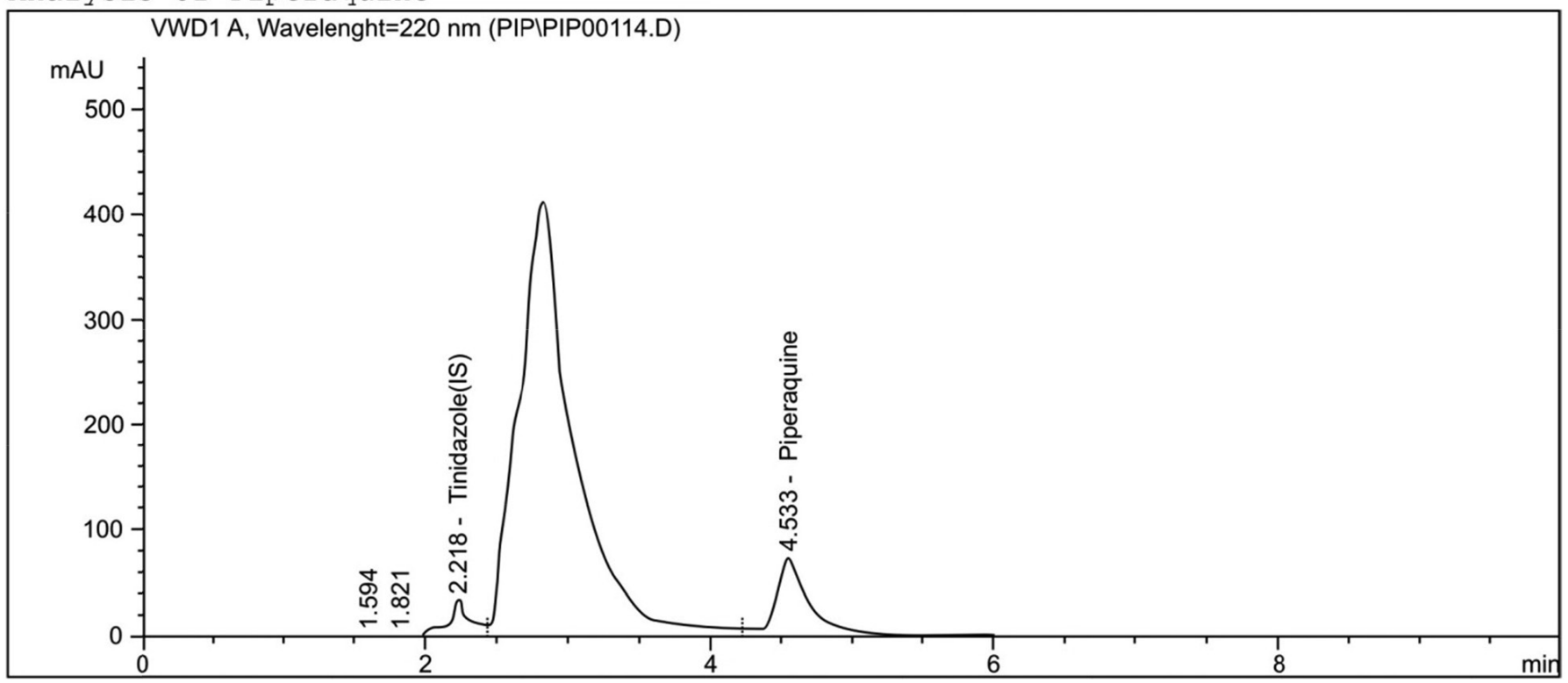

Figure 1. Representative chromatograph of the sample from intestinal perfusion containing PQ.

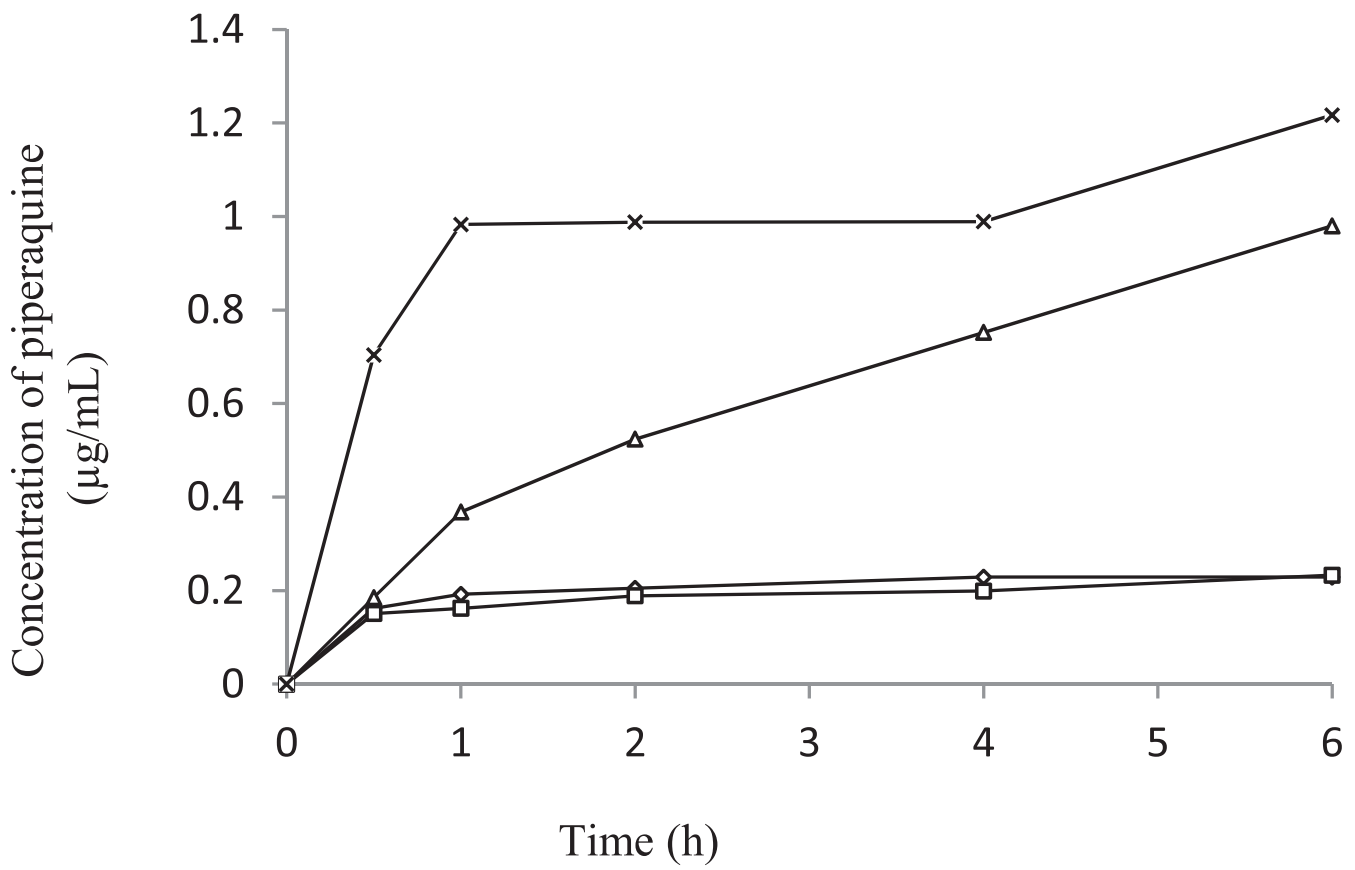

Figure 2. Permeation of PQ across duodenal/ileal intestinal epithelia ${ }_{x} \mathrm{ID}=\mathrm{DP}$ alone in ileum, $\square \mathrm{IDL}=\mathrm{DP}$ alone in ileum, $\Delta \mathrm{DD}=\mathrm{DP}$ alone in duodenum, and $\diamond \mathrm{DDL}=\mathrm{DP}+\mathrm{LMV}$ in duodenum).

appearance in organ bath was higher in the test than the control in the duodenal set-up. Similarly, LMV caused a higher $P_{\text {eff }}$ for the appearance of PQ in the organ bath for the ileal set-up $(p<0.05)$. In the luminal environment, the $P_{\text {eff }}$ disappearance for PQ revealed higher permeation of the analyte in the test than their respective controls $(p<0.05)$. No difference in the regional $P_{\text {eff }}$ of PQ for the test and the controls as revealed in Figure 3. The $P_{\text {eff }}$ appearance and $P_{\text {eff }}$ disappearance for PQ are illustrated in Figure 3. The area under the curve for 2 hours $\left(\mathrm{AUC}_{2}\right)$ post immersion in the test was lower than its control value in the duodenum set-up. Similarly, a lower $\mathrm{AUC}_{2}$ value was observed for the test in the ileal experiment. Table 1 presents some pharmacokinetic indices for PQ transport across the intestinal barrier. The test revealed that there was no significant difference in the oral absorption rate of PQ compared with the control in the duodenal set-up $(p=0.130)$ while there was higher rate due to LMV in the ileal set-up $(p=0.049)$. The $C_{\max }$ in the duodenal set-up showed a lower value than its control $(p=0.015)$. Similarly, LMV revealed lower $C_{\max }$ value for PQ in organ bath in the ileal set-up $(p=0.009)$. 

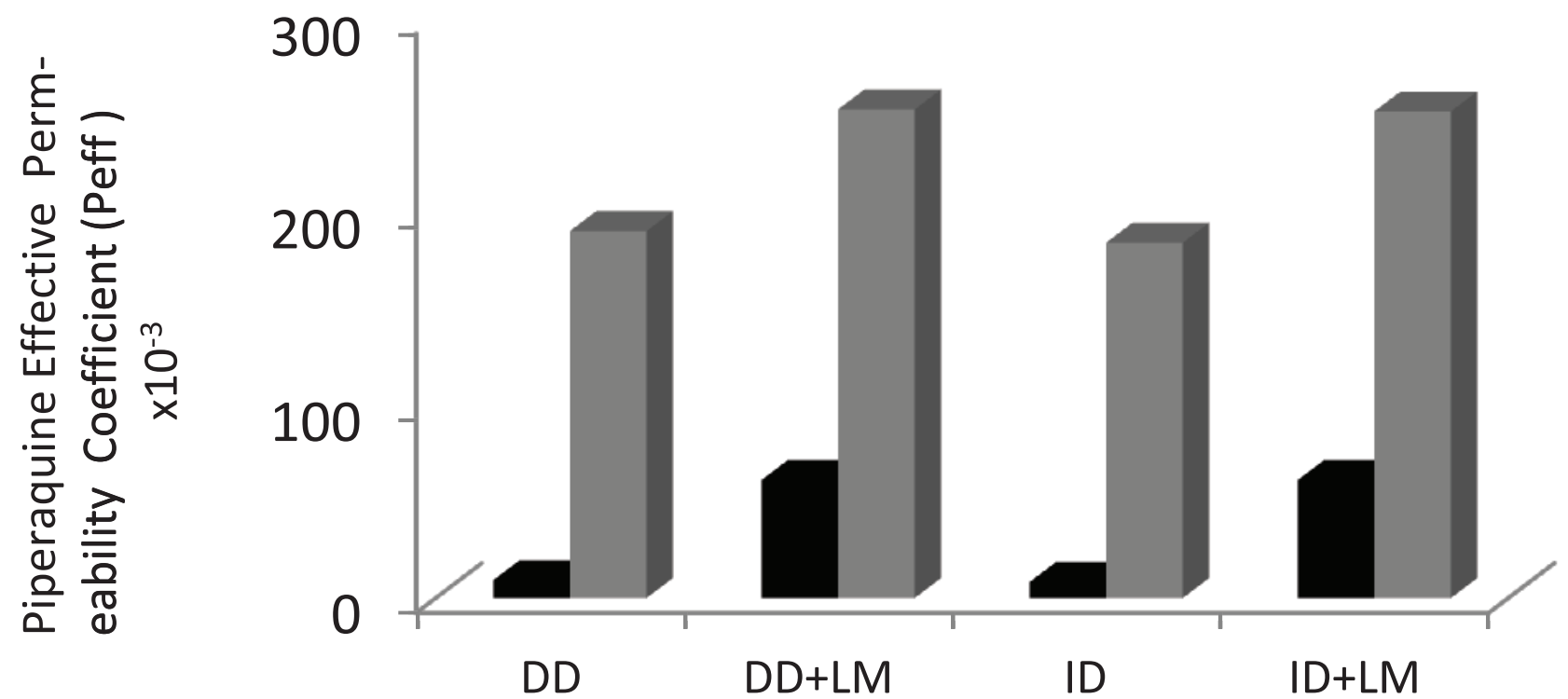

Figure 3. Effective permeability coefficient $\left(P_{\text {eff }}\right)$ of PQ calculated for appearance in an organ bath and $\square$ disappearance from the lumen, (DD $=$ DP alone in the duodenum, DD + LM = DP with LMV in the duodenum, ID = DP alone in ileum, and ID + LMV= DP with LMV in ileum).

\section{DISCUSSION}

The oral route is the major and preferred route of drug delivery for the treatment of chronic diseases due to convenience and improved patient safety (Verma et al., 2010). This study, therefore, was designed to assess the oral delivery of PQ across the intestinal region in the presence of another simultaneously administered drug. The importance of the study was to highlight the pharmacokinetic implications of co-prescribing medications in co-morbidities. The subject of DDI following orally administered therapy is gaining relevance in recent years as one drug is often co-prescribed with others as studied in this work (Bazzoni et al., 2015). PQ investigated in this study is an important partner in DP combination for malarial treatment strategies (Moore et al., 2008). There is a paucity of detailed preclinical and clinical pharmacokinetic data to link PQ intestinal absorption with its consequent serum concentration alongside cases of efficacy or safety (Tarning et al., 2008). LMV was selected for this study as it is the first nucleoside analog registered for the treatment of chronic hepatitis B (Henry et al., 2012), prevention of perinatal hepatitis B viral infections (Margolis et al., 1995), and transmission of HIV (Caudros et al., 2011; Mave et al., 2014). This study, therefore, seeks to assess the permeation or diffusion of PQ across intestinal epithelium in the co-formulated state (i.e., DP) on co-administration with LMV.

This preliminary ex vivo method was employed for the study because of the inherent advantages. These include simplicity and convenience of operation, as the experimental conditions and environment are easy to control alongside the obtainment of reproducible outcomes. The test set up revealed PQ disappearance from intestinal lumen producing a striking reduction in values compared with their control. It appeared, therefore, that LMV caused mobilization of PQ from the luminal space into the epithelial environment, adjudging by the ka for PQ disappearance value. This explanation is expected to hold for the high values of ka appearance in TS but negated by the low AUC and $C_{\max }$ values when compared with their respective controls.

AUC values of PQ for 2 and 6 hours post immersion were to assess the promptness and extent of PQ permeation, respectively. Malaria being an acute febrile illness requires prompt blood level antimalarial agents; hence, the co-formulation design of dihydroartemisinin with PQ in DHA. Dihydroartemisinin, on the other hand, has a short half-life of 2 hours (Rijken, 2011). The extent of PQ diffusion will reinforce the rapid action required from the partner drug. Previous researchers have highlighted the low

Table 1. Kinetics of PQ release for the media conditions.

\begin{tabular}{|c|c|c|c|c|c|}
\hline \multirow{3}{*}{\multicolumn{2}{|c|}{ Parameters }} & \multicolumn{4}{|c|}{ Media conditions } \\
\hline & & \multicolumn{2}{|c|}{ Duodenum } & \multicolumn{2}{|c|}{ Ileum } \\
\hline & & DP and LMV & DP alone & DP and LMV & DP alone \\
\hline \multicolumn{2}{|c|}{$\mathrm{Ka}\left(\right.$ hour $\left.^{-1}\right)$} & $0.0153 \pm 0.0032$ & $0.0023 \pm 0.0002$ & $0.0153 \pm 0.0008$ & $0.0020 \pm 0.0003$ \\
\hline \multicolumn{2}{|c|}{$\left(C_{\max }\right) \pm \mathrm{SEM}$} & $0.2240 \pm 0.0015$ & $0.9800 \pm 0.0025$ & $0.2440 \pm 0.0023$ & $1.2170 \pm 0.0070$ \\
\hline \multirow{3}{*}{$R^{2}$ values } & Zero & 0.9438 & 0.4638 & 0.5169 & 0.5645 \\
\hline & First & 0.2497 & 0.1017 & 0.0047 & 0.0757 \\
\hline & Second & 0.1776 & 0.0258 & 0.0135 & 0.0108 \\
\hline
\end{tabular}

NB: $\mathrm{C}_{\max }$ and SEM represent the maximum concentration attained in an organ bath and standard error of the mean of treatments, DP and LMV represent dihydroartemisinin-piperaquine and lamivudine, respectively. Ka represents the absorption rate constant. 
oral bioavailability of PQ in different population pharmacokinetic studies (Ashley et al., 2004). The success of this co-formulation on simultaneous administration with LMV will depend on the DDI at the absorptive site. $\mathrm{AUC}_{2}$ and $\mathrm{AUC}_{6}$ were significantly lower than their respective control values, an indication of DDI at the intestinal uptake/permeation level. This significant reduction in the overall drug permeation becomes noteworthy more so as LMV mobilized significantly PQ uptake. The evident increase in $\mathrm{Ka}$ values and reduction in AUC values due to LMV is an indication of "trapping" of PQ within the membrane or reverse transport of PQ back into the epithelium from the TS.

LMV permeates through the intestinal tissues by passive diffusion or actively transported by uptake transporters termed the solute carrier superfamily including (SLC22A1, SLC22A2, and SLC22A3) and has a high oral bioavailability and high volume of distribution (Whirl-Carrillo et al., 2012). It is also actively transported out of the cell by efflux transporters $\mathrm{ABCB} 1, \mathrm{ABCC} 1$, $\mathrm{ABCC} 2, \mathrm{ABCC} 4$, and $\mathrm{ABCG} 2$. In its monophosphate form, it is transported out of the cell by ABCG2 (Whirl-Carrillo et al., 2012). It has been reported that PQ, like LMV, is majorly absorbed by passive diffusion (Yuen et al., 1995). PQ has an intrinsic poor aqueous solubility that constitutes major limitations to its successful oral drug delivery (Sharma et al., 2016). The co-administration of LMV with PQ sharing the same transepithelial transport mechanism (i.e., passive diffusion) has been shown to reduce the permeation of PQ in this ex vivo experiment. A rapid decline in the susceptibility of P. falciparum to DP has been reported recently and this may not be unconnected with the sub-optimal permeability of the actives in DP, especially PQ (Thanh et al., 2017).

LMV has been reported to cause pancreatitis, infrequently in adults but more common in pediatric patients (Suzuki et al., 2014). This physiological influence alongside widely reported intestinal membrane irritation may be responsible for membrane permeability property changes leading to altered intestinal permeation of PQ. Other major reported intestinal side effects are nausea, vomiting, and diarrhea (Neuman et al., 2012). The co-administration of LMV with other drugs (i.e., antimalarial agents which have co-morbidity with HIV or HBV infections) will require a proper assessment to optimize therapy.

This study also revealed a significant reduction in PQ permeation across duodenal epithelium in the presence of LMV as revealed by the AUC values (Table 2). Researchers have recommended spacing out the time for the administration of drugs such as 3-hydroxyl-3-methylglutaryl coenzyme A reductase inhibitors with LMV (Bader and Kober, 2010) in order to prevent DDIs. Similarly, there is the need to assess the effect of LMV on the bioavailability of PQ in DP on concurrent administration in the light of the recurrent antimalarial resistance reported across the globe.

Table 2. Area under curve (AUC) at 2 and 6 hours for the intestinal regions and media conditions.

\begin{tabular}{lcccc}
\hline \multirow{2}{*}{$\begin{array}{l}\text { Media } \\
\text { condition }\end{array}$} & \multicolumn{2}{c}{$\mathbf{A U C}^{2}\left(\boldsymbol{\mu g} . \mathrm{minute}^{-1}\right)$} & \multicolumn{2}{c}{$\mathrm{AUC}^{6}\left(\boldsymbol{\mu g} \cdot \mathrm{minute}^{-1} \mathbf{I}^{-1}\right)$} \\
\cline { 2 - 5 } & Duodenum & Ileum & Duodenum & Ileum \\
\hline Test & $0.3447 \pm 0.0172$ & $0.3036 \pm 0.0120$ & $1.2868 \pm 0.6725$ & $0.7425 \pm 0.0089$ \\
Control & $0.6198 \pm 0.0083$ & $1.5408 \pm 0.4275$ & $3.3975 \pm 0.3638$ & $5.6603 \pm 0.1073$ \\
\hline
\end{tabular}

$\mathrm{NB}: \mathrm{AUC}_{2}$ and $\mathrm{AUC}_{6}$ represent area under curve for $0-2$ hours and $0-6$ hours, respectively.
The $P_{\text {eff }}$ of LMV is in the range of drugs with high intestinal permeability indicating that LMV readily crosses the intestine. Such is the nature of drugs belonging to BCS Class 1. The drug PQ has been reported to be of low bioavailability as shown in passive diffusion across intestinal epithelium and this is dependent on many pharmacokinetic characteristics such as lipophilicity, molecular weight, and hydrophobic bonding. The combination of the two drugs will mean that LMV suppresses the passive diffusion of the poorly water-soluble PQ. The absorption of drugs via the oral route is always under examination due to the fact that unhindered diffusion and consequent good bioavailability indicates that the drug will reach systematic circulation (Hetal et al., 2010).

In an in vitro study previously reported by Awofisayo et al. (2018), there was no chemical interaction between LMV and any of the actives in DP using Fourier transform infrared spectroscopic analysis and assessment of troughs and peaks observed. It, therefore, suffices that the DDI between LMV and DP involves a physiological mechanism (i.e., membrane absorption characteristics alteration).

\section{CONCLUSION}

This study revealed that LMV reduced the intestinal permeability of PQ from DP on co-administration. This intestinal permeability has been demonstrated in the duodenum and ileum which shows the cumulative influence of LM on PQ. The novelty of this work is highlighted in the recommendation of spacing apart of drug dosing in the cases of co-prescribing of the investigated drugs. This will help against sub-optimal therapeutic concentrations of PQ in antimalarial therapy leading to parasitic resistance.

\section{CONFLICT OF INTEREST}

The authors declare that they have no conflict of interest.

\section{FUNDING}

The research was sponsored by Tetfund merged intervention 2015-2016, an award given to Sunday Olajide Awofisayo.

\section{ACKNOWLEDGMENTS}

The authors express their thankfulness to the Management of Central Research Laboratory, University of Lagos for the laboratory space, PD Ojobor for the technical assistance, and Ugochukwu I Okoye for the laboratory assistance.

\section{REFERENCES}

Antunes F, Andrade F, Ferreira D, Nielsen HM, Sarmento B. Models to predict intestinal absorption of therapeutic peptides and proteins Curr Drug Metab, 2013; 14(1):4-20.

Ashley EA, Krudsood S, Phaipun L, Srivilairit S, McGready R, Leowattana W, Hutagalung R, Wilairatana P, Brockman S, Looaresuwaan F, Nosten F, White NJ. Random controlled dose-optimization studies of dihydroartemisinin-piperaquine for the treatment of uncomplicated multidrug resistant falciparum malaria in Thailand. J Infect Dis, 2004:1773-82.

American Medical Association (AMA). World Medical Declaration of Helsinki Ethical Principles for Medical Research involving Human Subjects. J Am Med Assoc, 2003; 310(20):2191-4.

Awofisayo SO, Arhewoh MI, Okhamafe AO. In vitro interaction of food component with Artemether-Lumefantrine tablet. Int J Curr Res Rev, 2018; 10(1):22-6. 
Bader T, Korba B. Simvastatin potentiates the antihepatitis B virus activity of FDA-approved nucleoside analogue inhibitors in vitro. Antiviral Res, 2010; 86(3):241-5.

Bazzoni G, Marengoni A, Teltamanti M, Franchi C, Pasina L, Djade CD, Fortino I, Bortolotti A, Merlino L, Nobili A. The drug prescription network: a systemic-level view of drug co-prescription in communitydwelling elderly people. Rejuvenation Res, 2015; 18(2):153-61.

Chapman KL, Wilson S. Pharmaceutical toxicology: designing studies to reduce animal use, while maximizing human translation. Regul Toxicol Pharmacol, 2013; 66(1):88-103.

Centre for Drug Evaluation and Research (CDER). United States Department of Health and Human Services, Food and Drug Administration. Guidance for Industry Drug Interaction StudiesStudy Design, Data Analysis, Implication for Dosing and labeling Recommendation, February 2012. Available via http://www.fda.gov/Drugs/ GuidanceComplianceRegulatoryInformation/Guidances/defeault.htm (Accessed 10 April 2017).

Caudros DF, Branscum AJ, Crowley PH. HIV-Malaria coinfection: effects of malaria on the prevalence of HIV in East sub-Saharan Africa. Int J Epidemiol, 2011; 40:931-9.

Department of Health and Human Services (DHHS). Guidelines of panel on antiretroviral for adults and adolescents. Guidelines for the use of antiretroviral agents. 2015. Available via https://adsinfo.nih.gov/contentfiles/ Ivguidelines/adultandadoescentsgl.pdf (Accessed 10 March 2017).

Foca E, Odolini S, Brianese N, Carosi G. Malaria and HIV in adults: when the parasites run into the virus. Mediterr J Haematol Infect Dis, 2012; 4(1):e2012032; doi:10.4084/MJHID.2012.032

German P, Greenhoise B, Coates C, Dorsey G, Rosenthal PJ, Charlebois E. Hepatotoxicity due to a drug interaction between amodiaquine plus artesunate and efavirenz. Clin Infect Dis, 2007; 44:889-91.

Gupta AK, Sehrawat A. Bioavailability enhancement of poorly water soluble drugs: a review. IJPLS, 2011; 2(3):640-50.

Henry OJ, Lagoro KD, Orachi CG. Prevalence of malaria and treatment seeking behaviours among pregnant women in postconflict internally displaced persons' camp in Gulu district. ISRN Pub Health, 2012: 1-5 Article ID 164935. http://DX.doi.org/10.5402/2012.

Hetal T, Bimehesi P, Sneha T. A review of techniques for oral bioavailability enhancement of drugs. Int J Pharm Rev Res, 2010; 4(3):201-23.

Li L, Dong, WJ, Sheng L, Xia XJ, Li Y, Liu YL. Preparation, formation mechanism and preliminary evaluation of oral absorption of a Biocyclol-phospholipid complex. Yao Xue Xue Bao, 2014; 49(11):1600-6.

Luo Z, Liu. Y, Zhao B, Tang M, Dong H, Zhang L. Ex vivo and in situ approaches used to study intestinal absorption. J Pharmacol Toxicol Method, 2013; 68(2):208-16.

Mave V, Kadam D, Kinikar A, Gupte N, Bhattacharya D, Bharadadwaj R. Impact of maternal hepatitis B virus co-infection on mother-to-child transmission of HIV. HIV Med, 2014; 15:347-54.

Mori AT, Ngalesoni F, Norheim OF, Robberstad B. Cost effectiveness of dihydroartemisinin-piperaquine with artemetherlumefantrine for treating uncomplicated malaria in children at a district hospital in Tanzania. Malar J, 2014; 13:363-70.

Margolis HS, Coleman PJ, Brown RE, Mast EE, Sheingold SH, Arevalo JA. Prevention of hepatitis B virus transmission by immunization: an economic analysis of current recommendations. JAMA, 1995; 274(15):1201-8.

Moore SJ, Min X, Hill N, Jones C, Zaixing Z, Cameron MM. Border malaria in China: Knowledge and use of personal protection by minority populations for malaria control. A quesstionnaire-based survey. BMC Pub Health, 2008. 8: 344-54. https://doi.org/10.1186/1471

Neuman MG, Schneider M, Nanau RM, Parry C. HIVantiretroviral therapy induced liver, gastrointestinal and pancreatic injury.
Int J Hepatology, 2012:1-23. doi:10.1155/2012/760706 (Accessed 23 October 2017).

Oshikoya KA, Oreagba IA, Lawal S, Awodele O, Ogunleye OO, Senbanjo IO, Olayemi SO, Ezeaka VC, Temiye EO, Adeyemo TA, Opanuga $\mathrm{O}$, Lesii OA, Akanmu SA. Potential drug interactions in HIV-infected children on antiretroviral therapy in Lagos, Nigeria. HIV AIDS (Auckl), 2014; 6:49-59.

Piscitelli SC, Galliciano KD. Interactions among drugs for HIV and opportunistic infections. N Engl J Med, 2001; 344(13):984-96.

Qureshi S. Drug interactions with antiretroviral therapy, 2016. Available via http://emedicine.Medscape (Accessed 12 February 2018)

Rijken MJ, McGready R, Phyo AP, Lindergardh N, Tarning NL, Than HH, Mu O, Win AK, Singhasivanon P, White N, Nosten F. Pharmacokinetics of dihydroartemisinin and piperaquine in pregnant and non-pregnant women with uncomplicated falciparum malaria. Antimicrob Agents Chemother, 2011; 55(12):5500-6.

Sharma M, Sharma R, Jain DJ. Nanotechnology based approaches for enhancing oral bioavailability of poorly water soluble antihypertensive drugs. Scientifica, 2016; 1:1-12. doi:10.1155/2016/8525679

Shugart S, Benet LZ. The role of transporters in the pharmacokinetics of orally administered drugs. Pharm Res, 2009; 26(9):2039-54.

Suzuki M, Sai JK, Shimizu T. Acute pancreatitis in children and adolescents. W J Gastroenterol Pathophysiol, 2014; 5(4):416-20.

Tarning J, Ashley EA, Lindegardh N, Stepniewska K, Phaiphun L, Day PJ, McGready R, Ashton M, Nosten F, White NJ. Population pharmacokinetics of piperaquine after two different treatment regimens with dihydroartemisinin-piperaquine in patients with Plasmodium falciparum malaria in Thailand. Antimicrob Agents Chemother, 2008; 52(3):1052-61.

Thanh NV, Thuy-Nhien N, Tuyen NTK, Tong NT, Nha-Ca NT, Dong LT, Quang HH, Farrar J, Thwaites G, White NJ, Wolbers M, Hien TT. Rapid decline of the susceptibility of Plasmodium falciparum to dihydroartemisinin-piperaquine in the south of Vietnam. Malar J, 2017; $16: 27$.

Tseng A. Interactions between acid-reducing agents and antiretrovirals. Toronto General Hospital, Toronto, Ontario, 2015. Available via http://www.hivclinic.ca (Accessed 2 March 2018).

Uriel A, Lewthwaite P. Malaria therapy in HIV: Drug interactions between nevirapine and quinine. Int J STD AIDS, 2011; 22(12):768-75; doi:10.1258/ijsa2009.009489

Verma P, Thakur AS, Deshmukh KH, Jha AK, Verma S. Routes of drug administration. Int J Pharm Sci Res, 2010; 1(1):54-9.

Whirl-Carrillo M, McDonagh EM, Hebert JM, Gong L, Sangkuhl $\mathrm{K}$, Thorn CJ, Altman RB, Patel JR, Barve KH. Intestinal permeability of lamivudine using single pass intestinal perfusion. Indian J Pharm Sci, 2012; 74(5):478-81.

Yuen GJ, Morris DM, Mydlow PK, Haidar S, Hall ST, Hussey EK. Pharmacokinetics, absolute bioavailability, and absorption characteristics of lamivudine. J Clin Pharmacol, 1995; 35(12):1174-80.

Zhang C, Mcllerton H, Pen Y. Population pharmacokinetics of lopinavir and ritonavir in combination with rifampicin-based antitubercular treatment in HIV-infected children. Antiviral Ther, 2012; 25-33.

How to cite this article:

Awofisayo SO, Agboke AA, Essien EN, Igwe CN. Intestinal permeability studies for piperaquine from dihydroartemisinin - piperaquine antimalarial product in the presence of lamivudine. J Appl Pharm Sci, 2018; 8(11): $103-108$. 